\title{
SubJeTIVIDAde $\&$ COMPLEXIDAde NA CLÍNICA PSICOLÓGICA: SUPERANDO DICOTOMIAS ${ }^{\star}$
}

http://dx.doi.org/10.1590/1984-0292/971

Maurício S. Neubern ${ }^{\star \star}$

Universidade de Brasília, Brasilia, DF, Brasil

\section{RESUMO}

O presente trabalho busca propor conceitos fundamentados no pensamento complexo para as dicotomias clássicas de corpo-mente e indivíduo-social. Partindo de uma breve ilustração clínica, destaca-se como os processos subjetivos são encarnados na vivência corporal das pessoas, por meio da noção de subjetividade, e como existe uma flexibilização maior entre individual e social por meio da noção de sujeito. Conclui-se que, para que essa noção complexa e dialética seja implementada, não é suficiente que se proponha um novo conceito, mas um conjunto de conceitos que, irmanados dentro de uma lógica complexa, proporcionem uma nova forma de pensar a clínica.

Palavras-chave: clínica psicológica; complexidade; subjetividade; sujeito.

\section{SubJECTIVITY \& COMPLEXITY IN CLINICAL PSYCHOLOGY:}

\section{OVERCOMING DICHOTOMIES}

\begin{abstract}
This paper proposes concepts founded on complex thought for the classic dichotomies of body-mind and individual-social. Beginning with a brief clinical example, it highlights how subjective processes are personified in people's bodily experiences, by way of the notion of subjectivity, and how there is greater flexibility between the individual and social via the notion of subject. It concludes that in order for this complex and dialectical concept to be implemented, it is not enough to propose a new concept, but rather a set of concepts that when grouped within a complex logic, allows for a new way of approaching the practice.

Keywords: clinical psychology; complexity; subjectivity; subject.

\footnotetext{
^Este artigo deriva do projeto "Hipnose, subjetividade e dores crônicas: Construindo o contexto terapêutico" aprovado pelo Comitê de Ética da Universidade de Brasília (CEP IH). Todos os cuidados éticos foram rigorosamente obedecidos para o desenvolvimento desta pesquisa. Agradecimento ao Decanato de Pós-Graduação e Pesquisa da Universidade de Brasília pelo financiamento de parte deste projeto. Universitário Darcy Ribeiro - Asa Norte. 70910-900 - Brasilia, DF - Brasil.

E-mail: mauricio.neubern@gmail.com
}

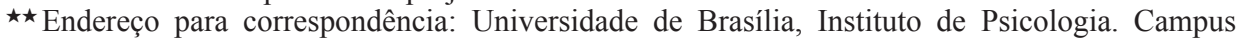


O advento da Psicologia como ciência respaldada pelo saber moderno implica na construção de diferentes formas de disjunção, no tocante à construção do conhecimento (MORIN, 1991, p. 224-227; PAGES, 2001, p. 57). Se, por um lado, existe uma propensão para interligar, sob altos custos epistemológicos, o saber consagrado da ciência, respaldado numa visão objetiva e isomórfica de conhecimento, com noções marginalizadas por ela (como qualidade, sujeito, consciência, subjetividade), por outro, o conhecimento torna-se separado em diferentes momentos, estabelecendo relações de oposição nem sempre conciliáveis entre seus momentos, como teoria e método, pesquisa básica e pesquisa aplicada, reflexão e prática e até mesmo entre clínica e ciência (GONZALEZ REY, 1996, p. 57-61). Numa tal perspectiva, na qual há uma tentativa forçada de aproximação da subjetividade com relação à Physis, a subjetividade é esvaziada de seu teor qualitativo e antropológico, convertendo-se em psiquismo, cujas dimensões passam a se relacionar ora de forma rigidamente hierárquica, ora pela dissolução completa da dimensão secundária.

Tal processo histórico e epistemológico de construção da psicologia moderna implica na produção de relações de dicotomia entre diferentes polos da subjetividade humana, ou seja, relações comumente hierarquizadas e rígidas, com o privilégio de um polo em detrimento do outro. A concepção de psique torna-se gradativamente separada em diferentes dicotomias, como histórico-atual, universal-singular, essência-existência, determinismo-livre-arbítrio, internoexterno, consciente-inconsciente, individual-social, corpo-alma (NEUBERN, 2003, p. 83). Assim, enquanto determinadas escolas, como a psicanálise freudiana, concebem a psique em termos da primazia do inconsciente, do interno, do individual e do passado, numa ótica determinista, colocando seus polos opostos numa condição secundária, outras, como o psicodrama, a concebem em termos do consciente, do relacional e do momento presente como possibilidade de criação (NEUBERN, 2004, p. 35-38).

Não raro, semelhantes separações impõem uma lógica de pensar inflexível que não acompanha a diversidade de processos subjetivos singulares construídos pelo sujeito em sua vida cotidiana, proporcionando uma relação clínica em que as construções teóricas e intervenções do terapeuta se constituam como imposições narrativas sobre a experiência dos clientes, o que pode redundar em consequências que derivam de uma profunda desqualificação do mundo do outro, como a ruptura de vínculos, a estigmatização e a iatrogenia (ERICKSON, 1983, p. 54).

Dentre as diversas dicotomias, a oposição mente-corpo passa a ocupar um lugar central nos diferentes momentos de construção de conhecimento psicológico. O corpo se constitui, gradativamente, como um terreno médico, perpassado pelas expectativas de controle social dos desviantes (FOUCAULT, 2000 , p. 125) e permeado por óticas mecanicistas e lineares que parecem desabitá-lo das noções de experiência vivida (MERLEAU-PONTY, 2008, p. 101). Esse verdadeiro exorcismo imposto ao corpo como campo de reflexão e conhecimento coincide com as tentativas de apropriação da psique por meio de metáforas oriundas de outros campos já consagrados pelo saber moderno, como 
a engenharia, no caso do aparelho psíquico psicanalítico, a computação, no caso dos cognitivistas e alguns sistêmicos, a experimentação, como o laboratório para os comportamentais (GOOLISHIAN; ANDERSON, 1996, p. 192-193).

Logo, entre dois campos gradativamente separados e forjados dentro de uma ótica objetivista, corpo e mente tornaram-se dimensões cada vez mais distantes e apropriadas de determinados saberes, como a medicina e a psicologia, cujas relações, em termos epistemológicos e institucionais, não são simples nem isentas de obstáculos. Daí que as tentativas de relação entre corpo e mente são marcadas por ideias lineares, causalistas, deterministas e de superposição (MERLEAUPONTY, 2005, p. 5-8) que criam grandes barreiras para uma compreensão mais abrangente de diferentes temáticas clínicas contemporâneas - depressão, dores e doenças crônicas, promoção de saúde, psicoses, gênero, violência, dentre outros.

Outra dicotomia de grande impacto na construção do saber psicológico é a oposição individual-social na qual o primeiro é associado ao mundo interno da pessoa e o segundo a toda a rede externa de relações sociais (GONZALEZ REY, 2004, p. 71). Uma vez que o psicológico passa a se constituir como propriedade do indivíduo, há um grande número de perspectivas teóricas que se associam a noções como essência e natureza humana, de maneira a dissociar o sujeito de toda a trama e riqueza de sua participação dialética no mundo social (GONZALEZ REY, 2007, p. 41-52). Semelhante distanciamento do mundo social, além dos problemas ideológicos, traz graves implicações teóricas e clínicas, uma vez que impede o acesso a importantes momentos da constituição subjetiva ligadas ao social, como em termos de identidade (ELLIOT; LEMERT, 2009, p. 17-40), corpo (CSORDAS, 2002, p. 58-60) e a própria produção de sentidos subjetivos (GONZALEZ REY, 2011, p. 31).

Por outro lado, na tentativa de re-pensar o problema, algumas propostas teóricas acabam se posicionando no extremo que privilegia o social e a linguagem em detrimento do individual interno que, para eles, não seria mais que uma produção discursiva (GERGEN, 1996, p. 21; WHITE, 2007, p. 23-38). Desse modo, processos tradicionalmente concebidos como pertencentes ao mundo interno, como o sujeito, a produção de sentidos, a imaginação e a identidade, são transportados para o relacional, onde tudo se constrói a partir do discurso e o que não se enquadra em suas concepções, simplesmente deixa de existir.

Diante desse quadro, o presente trabalho busca traçar algumas possibilidades teóricas e conceituais fundamentadas pelo pensamento complexo (MORIN, 1990, p. 163-180) com o intuito de propor novas formas de articulação dialógica entre pares de dimensões corpo-mente e individual-social. Para tanto, parte-se de uma análise clínica e qualitativa (NEUBERN, 2004, p. 65; 2010, p. 520-522) das cenas de uma situação de psicoterapia de base hipnótica ${ }^{1}$ (ERICKSON; ROSSI, 1979 , p. 53) com diferentes imagens que remetem a uma situação de violência sofrida por uma paciente em sua infância. Tal processo de análise e reflexão será fundamentado em duas noções centrais. Por um lado, o conceito de configuração subjetiva (GONZALEZ REY, 2011, p. 31) que consiste num sistema subjetivo 
e complexo que implica na articulação entre diferentes processos, produzindo diferentes signos, ${ }^{2}$ que podem participar simultaneamente de processos que constituem um polo como dos processos que constituem seu par dialógico.

Por outro lado, tal análise envolverá também a noção de autonomia (MORIN, 1990, p. 287-298) que estabelece determinadas fronteiras entre os referidos polos, de maneira a conceber que, mesmo articulados, não desenvolvem uma relação de linearidade entre si, garantindo um funcionamento próprio e com certa independência mútua. Nesse sentido, propõe-se, quanto ao par de dimensões mente-corpo, a noção de subjetividade complexa (NEUBERN, 2010, p. 520), que significa conceber o corpo como território de produção vivida de diferentes ordens de processos subjetivos; e quanto ao par individual-social, propõe-se a perspectiva de um sujeito complexo (MORIN, 1990, p. 310; 2001, p. 77-88) que, apesar de habitado por processos do mundo social, não perde suas condições de identidade e autonomia, que o permitem, inclusive, um papel ativo na transformação da experiência interna e do mundo social.

\section{IlustraÇão Clí́nica}

Adriane, 57 anos, arquiteta, buscou terapia após uma crise conjugal, em que havia descoberto várias traições de seu marido. Relatou que esse comportamento de busca de uma amante do marido havia se desencadeado num momento de grande ascensão econômica e social da família, que culminou com a mudança para um bairro rico da cidade. Queixava-se de que o poder de decisão em assuntos importantes sempre cabia ao marido ("o dono do dinheiro"), como o papel de dona de casa por quem sempre optou em detrimento de sua carreira profissional e da superproteção pela qual educou seus filhos. A psicoterapia, de caráter hipnótico e breve, desenvolveu-se de modo satisfatório, de maneira a lhe possibilitar uma condição de autonomia e resolução emocional de grande relevância que lhe proporcionaram modificações significativas em termos pessoais e conjugais, como ainda dos sintomas de pânico e das dores oriundas de sua fibromialgia.

No entanto, durante uma visita ao dentista, Adriane deparou-se com uma situação inesperada, na qual, de forma espontânea, visualizou imagens de uma violência sexual sofrida na infância por parte de um tio materno, "o tio rico da família", quando contava com sete anos durante uma temporada na casa de sua avó. Logo que o dentista segurou seu maxilar e iniciou um procedimento microcirúrgico, vieram a sua mente as cenas em que o tio a segurava com força e apertava sua boca para que não emitisse ruídos ou falasse do que ocorria naquele momento. Até então, Adriane relatava não se lembrar de tais cenas, mas apenas da repulsa à figura de seu tio, e de algumas imagens sobre as quais sua avó, mãe e tias silenciavam-se (como quando apareceu com sangue encharcando o baixo ventre na camisola ou quando ficava trancada no sótão, dentro de casa), trazendo-lhe grande mal estar.

Semelhante experiência, de considerável sofrimento, fez com que o procedimento odontológico fosse adiado e Adriane buscasse, com urgência, a ajuda psicoterápica. Durante o transe hipnótico, o psicoterapeuta procedeu a uma técnica de divisão da experiência (ERICKSON, 1983, p. 236-237) em que 
a dor física seria separada das imagens e conteúdos emocionais, sendo ambos trabalhados paralelamente. Assim, enquanto o corpo poderia acionar seus recursos analgésicos para a região maxilar, o inconsciente poderia auxiliá-la a circunscrever as experiências ali trazidas, destacando os recursos diversos com a qual pôde lidar, enquanto menina, para poder seguir seu caminho, apesar de seu sofrimento. Suas escolhas saudáveis (no campo relacional, afetivo e espiritual), suas realizações profissionais e acadêmicas (sempre muito satisfatórias e prazerosas para ela), sua maternidade, seu círculo social, dentre outros, foram destacadas num processo de distorção do tempo (ERICKSON, 1983, p. 254262) que proporcionaram considerável impacto sobre seu cenário subjetivo, de maneira a reduzir, sobremaneira, a influência nefasta das experiências do abuso sexual. Sua própria capacidade de reprimir tais memórias durante muitos anos foi enfatizado como um recurso de proteção necessário que revelaria seu conteúdo apenas quando estivesse em condição de lidar com ele.

Num encontro seguinte, Adriane relatava uma intensa raiva que, ao longo da conversação hipnótica, tomou a forma de seu marido, cercado por vários objetos antigos de sua casa; ela sentiu-se profundamente aliviada ao poder, em transe, ensacar vários desses objetos (inclusive fotos de seu marido) e jogá-los numa grande fogueira, comprazendo-se em ver grandes labaredas consumindo aquelas coisas velhas, ao mesmo tempo em que relatava "dizer poucas e boas" para seu marido. Num terceiro encontro, procedeu-se a uma retomada seqüencial do processo, sem proporcionar visualizações da cena do abuso, mas dos sentimentos que já estavam em trabalho; assim, da separação entre a dor do dente e as dores da alma, da visualização de cenas impregnadas de recursos e proteções, Adriane visualizou seu tio vestido como um palhaço branco e vermelho que ela jogava nas larvas de um vulcão e se admirava de como "aquele infeliz" demorava a derreter. Tais procedimentos parecem ter favorecido à paciente melhoras de grande relevância de modo a lhe possibilitar a retomada do tratamento cirúrgico dentário e uma grande redução da sensação de mal-estar "sem explicação" que, vez por outra, a acometia. Os sentimentos de revolta, indignação e exigência de reparação, ligados a um sentido subjetivo de "sentir-se roubada" pela família de origem, passaram, ${ }^{3}$ então, a conviver com uma postura ativa e de negociação no casamento, de maneira a rejeitar com veemência suas imposições. Pouco tempo depois a paciente estava em condições de receber alta.

\section{DA DICOTOMIA CORPO/MENTE À SUBJETIVIDADE}

Uma explicação provável para muitos psicólogos diante de uma situação como esta (JOHNSON, 1987, p. 28-37) seria a de que a semelhança entre as situações (do abuso e do dentista) poderia evocar, por mecanismos automáticos e condicionados, as memórias até então reprimidas do abuso sexual. Assim, quando a paciente, numa situação ameaçadora e estressante de cirurgia, fosse segura em sua boca por um homem instituído de poder, as terríveis imagens do passado viriam à tona com o conteúdo emocional de sofrimento que portavam. Essas explicações, embora possam oferecer algum poder explicativo, acabam por implicar num conjunto de perspectivas reducionistas caracterizadas pela 
superposição de experiências, como se o relatado pela paciente implicasse numa sequência de diagramas separados de sensações, esquemas, crenças e imagens desencadeados, talvez, pela semelhança de estímulos entre o ambiente do consultório e a cena do abuso.

Dentre as diversas limitações de tais perspectivas é possível destacar, de início, a ênfase no padrão em detrimento da produção subjetiva da pessoa (GONZALEZ REY, 2011, p. 31). Isto porque uma sequência de padrões entre sensações, esquemas, emoções, crenças e imagens pouco diz de quem é aquela pessoa, nem de como ela vivencia sua experiência, como sofre com ela, que realidades cria na relação com tal violência e, sobretudo, como produz sentido sobre a mesma. A pessoa Adriane continuaria diluída em meio a tal leitura, cuja sensibilidade teórica seria voltada para regularidades específicas, definidas externamente que poderiam ser úteis para um terapeuta ou pesquisador em termos da mudança de padrões ou de suas questões de pesquisa, mas que proporcionariam, facilmente, um distanciamento quanto a sua produção subjetiva cotidiana. Por outro lado, a superposição de funções mentais não explicita as formas de relação entre elas, elimina a dimensão dialética e vivida que as caracteriza, suprime a recursividade de suas interações e termina por manter uma acentuada distância entre corpo (destacado aqui pela sensação de dor da paciente) e mente (onde encontram morada tranquila funções como emoções, crenças e imagens).

No entanto, quando o corpo é considerado enquanto subjetividade (NEUBERN, 2009a, p. 305), suas diferentes experiências são concebidas a partir de seus próprios signos e sentidos subjetivos ao invés da ênfase em referências externas como padrões e funções mentais. O que importa em termos de compreensão clínica é o que estas expressões significam para o sujeito, considerando aqui que este "significar" pode abranger diferentes configurações e níveis de experiência (MERLEAU-PONTY, 2005, p. 217-222) e envolver diferentes produções de signos. É assim que a relação entre a dor no dente, a cena do consultório odontológico e o reaparecimento de vivências tão sofridas remete a uma articulação complexa entre estes níveis, envolvendo um jogo de forças físicas, com suas resultantes de equilíbrio do esquema corporal da região, um sistema vital e energético ligado à sensibilidade animal, com toda sua lógica instintiva de preservação e defesa e uma produção simbólica, emocional e cultural ligadas à mediação e produção de significados e sentidos subjetivos.

Uma única experiência, portanto, como as imagens vividas por Adriane, implica a interpenetração de diferentes sistemas configuracionais (ao invés da justaposição), com diferentes produções subjetivas de signos que obedecem a uma lógica própria (e não aos padrões traçados de fora por um pesquisador) que exigem um olhar que as qualifique a partir de suas próprias referências de mundo vivido. Isso significa que mesmo que o corpo possa se tornar objeto de reflexão e análise do sujeito, ele não consiste num sistema a parte ou numa instância exterior, como a corriqueira imagem segundo a qual o corpo seria uma máquina na qual o espírito adentra para poder pilotá-la. Ele é o espaço no qual o sujeito se re-inventa e se constitui, o território encarnado em que gera signos físicos e animais que só se qualificam, porém, enquanto humanos pela 
produção de sentidos subjetivos oriundos do simbolismo cultural, fundamentais na constituição de sua identidade, da qualificação de suas relações com os diferentes cenários sociais e das grandes temáticas de sua existência.

A perspectiva de uma subjetividade, nesse sentido, que toma o cenário de experiências do sujeito por guia, implica em dois princípios de grande importância para uma compreensão clínica. Por um lado, remete a uma lógica configuracional, que concebe uma articulação sistêmica e complexa entre diferentes processos vividos pelo sujeito que produzem variadas qualidades de signos. Desse modo, as imagens de abuso revividas por Adriane remetem à articulação de um conjunto de emoções ancoradas na carne (particularmente na região maxilar), habitada por todo um conjunto de esquemas corporais ligados ao desencadeamento de sensações, reflexos e memórias (GALLAGHER, 2005, p. 70-73) e toda uma produção simbólica de sua subjetividade social ligada à violência familiar, ao segredo, às produções de gênero, religião e sexualidade. A particularidade de tal configuração implicou ainda a relação experiências mais recentes da traição de seu marido, coincidindo significados de traição, dinheiro, ascensão social, engano e violência, ligados, no segundo momento do transe, à emoção dominante de ódio.

As imagens, portanto, integram-se a complexos sistemas de configurações, desenvolvendo relações recursivas com os mesmos. À medida que variam, novos arranjos configuracionais se constituem estabelecendo um campo de influências mútuas capazes de promover mudanças significativas na produção de novos signos e, particularmente, de sentidos subjetivos, tal como se verificou em suas mudanças terapêuticas. Desse modo, embora não se partilhe aqui inteiramente das perspectivas de Sartre (2005, p. 159-164), segundo quem as imagens seriam atos de consciência e não produções da subjetividade, tal proposta é de grande relevância ao propor as imagens como configurações de diferentes processos (símbolo, corpo e emoção), o que remete a uma unidade de experiência que mantém a diversidade heterogênea de seus constituintes.

Por outro lado, a subjetividade implica em diferentes possibilidades de autonomia (MORIN, 1990, p. 287) e criação em termos configuracionais, muitas das quais escapam à intencionalidade do sujeito. Concebe-se que a ação do sujeito em diferentes níveis desencadeia mudanças significativas, capazes de promover importantes e novos arranjos configuracionais da experiência. Tomando-se como base novamente a produção de imagens no setting terapêutico, tema já desenvolvido por eminentes psicoterapeutas do passado (DESOILLE, 1938, p. 33; ERICKSON, 1983, p. 218), torna-se possível conceber como semelhante ato remete a um conjunto de mudanças de valor nada desprezível para a paciente. Se, de um lado, as sugestões, sempre desenvolvidas de forma metafórica e indireta (ERICKSON; ROSSI, 1979, p. 218), parecem circunscrever a experiência impactante do abuso, delimitando-a numa região da subjetividade e promovendolhe diferentes formas de seqüência, de outro, elas evocam outros tipos de imagem ligadas a diferentes campos de configurações com qualidades emocionais e simbólicas largamente distintas da experiência de sofrimento da paciente. 
Uma vez que tais experiências são evocadas elas parecem ganhar maior espaço no cenário subjetivo de Adriane o que impacta suas configurações de sofrimento com outras formas de emoção, com diferentes arranjos de esquemas corpóreos e ainda com novas possibilidades de mediação simbólica. Semelhante processo de transe, onde a intenção deliberada da paciente varia de modo considerável, culmina com uma mudança qualitativa de grande importância para Adriane, que abrange diferentes tipos de produção subjetiva: o problema, antes escondido, torna-se algo explícito e tratável; a influência do pânico, como da fibromialgia, são significativamente dissolvidas; a experiência de abuso é dividida e manuseada pela paciente, colocada em novas seqüências e transformada em outras imagens; novas qualidades de produção subjetiva são trazidas à tona (por meio da evocação de outros tipos de experiências) e os sentidos de indignação e revolta, "sentir-se roubada" que emergem desse processo a impelem não apenas novas qualidades de produção, como a uma atitude de protagonista diante de suas demandas clínicas, como da promoção de uma nova pauta relacional diante de seu marido.

Face a tais questões, é possível conceber que as imagens não consistem em processos que se restrinjam ou à mente ou ao corpo, numa perspectiva dicotômica, mas transitam entre ambas as dimensões numa perspectiva dialógica (MORIN, 1990, p. 181-192; NEUBERN, 2004, p. 139-180). O caso da dor de dente em si aqui destacado, é muito ilustrativo nesse sentido uma vez que, numa região física do corpo ele configura elementos de toda uma vitalidade (como a dor, o repuxar em volta dos dentes, da gengiva e da face), o que é comumente associado ao orgânico, mas também traz elementos históricos de grande relevância, em forma de lembranças vivas de importantes acontecimentos do cenário de Adriane, o que seria em geral associado à mente. Desse modo, pode-se conceber aqui, através de toda uma teia complexa de configurações, como uma aparentemente simples dor de dente é também um processo mental (subjetivo), além de corporal, e como acontecimentos traumatizantes de seu passado, além de mentais, são também encarnados em seu corpo. Se o corpo é imbuído de história, cultura, em suma de subjetividade, a constituição subjetiva de uma pessoa não consiste em entidade etérea, mas encarnada num corpo, onde estabelece um dos momentos mais importantes de sua construção enquanto sujeito.

\section{DA DICOTOMIA INDIVÍdUO/SOCIAL AO SUJEITO COMPLEXO}

Uma situação como a aqui relatada poderia favorecer a que muitos psicólogos, imbuídos pela dicotomia individual/social (GONZALEZ REY, 2004, p. 7-22), considerassem a violência sofrida por Adriane como um fenômeno social e externo com repercussões em seu interior psicológico. Assim, não só os atos de violência, mas também sua manutenção por meio de uma dinâmica familiar e narrativa específica seriam eventos pautados numa lógica relacional e social, com implicações psicológicas individuais de caráter psicodinâmico, também merecedoras de atenção psicoterápica (FERRARI; VENCINA, 2002, p. 84-87). A depressão, as tendências autodestrutivas, a construção negativa da identidade, as tendências de envolvimento em relacionamentos abusivos 
seriam processos a bem dizer internalizados e desenvolvidos numa perspectiva psicodinâmica pela vítima, embora fossem alimentadas e até mantidas, durante um tempo, por determinados padrões relacionais.

Numa proposta de ruptura com essa lógica, alguns terapeutas (ANDERSON, 1997, p. 70; WHITE, 2007, p. 23) poderiam mesmo considerar tais implicações de sofrimento ocasionadas pelo abuso enquanto fenômeno narrativo e relacional, sem qualquer referência a fenômenos internos e psíquicos. Por considerarem o self um processo construído no relacional e o mundo interno como mero discurso de origem sociocultural (GERGEN, 1996, p. 125-150), as consequências do abuso antes listadas nada mais seriam que construções narrativas que tiveram lugar em pautas relacionais específicas as quais, portanto, poderiam ser desconstruídas no processo dialógico da psicoterapia.

Malgrado a relevância clínica e teórica de tais contribuições (NEUBERN, 2004, p. 145-148), é possível conceber que as mesmas recaem na dicotomia dominante nas propostas psicológicas, seja por manter o individual e o social como campos separados - como na ótica psicodinâmica, seja por estabelecer uma hierarquização tão radical entre ambos, na qual o individual é dissolvido nas pautas relacionais - como ocorre com os narrativos. Nesse sentido, perde-se o caráter dialético e complexo de experiências como a de Adriane, uma vez que as cenas e imagens por ela relatadas, como a riqueza de seus processos vividos seriam delegados a uma produção imaginária e subjetiva de teor interno e individual ou encerradas em pautas relacionais e discursivas que esgotariam, de forma linear, a riqueza de suas produções individuais em construções narrativas de cunho social. Torna-se, portanto, possível destacar que, de um ponto de vista teórico e clínico, uma tal dicotomia pode desfavorecer uma compreensão mais apurada a respeito da vivência de pacientes como Adriane, sobretudo no que diz respeito à sua produção de sentidos subjetivos em relação a importantes processos de sua experiência.

No entanto, caso se considere uma perspectiva complexa de sujeito (GONZALEZ REY, 2007, p. 162-164; MORIN, 2001, p. 321; NEUBERN, 2010, p. 522), semelhante problemática pode ser desenvolvida em torno de duas noções centrais: a cena subjetiva e a autonomia. No primeiro caso, tem-se que uma cena, tal como relatada por Adriane, envolve uma dialética complexa de processos de teor individual e social que não permitem uma separação teórica abrupta e impositiva, mas se organizam sob uma lógica configuracional. Isso porque ao mesmo tempo em que a paciente produz e desenvolve sentidos subjetivos e uma gama de processos e signos muito singulares a partir dessa vivência, há também uma dimensão de fabricação social presente na forja da cena que é decisiva para o desenvolvimento de tais experiências. As cenas consistem num conjunto de imagens que remetem a uma dialética na qual o mundo social, em suas dimensões micropolíticas e culturais, passa a habitar o mundo vivido do sujeito (CSORDAS, 1997, p. 141-144), integrando-se a seus sistemas de configurações.

Elas se integram a sentidos e signos subjetivos específicos, reproduzem, de algum modo, os dispositivos sociais e personagens que as antecederam e criam referências relacionais do sujeito quanto a si e quanto a importantes temas de sua 
vida. Em suma, ao mesmo tempo em que são apropriadas, isto é, configuradas e vivenciadas de maneira muito singular por cada pessoa, as cenas também se constituem como produções do mundo social, o que permite considerar que o cenário vivido pelo sujeito está longe de ser o campo solitário de um eu homogêneo, por consistir num palco plural e heterogêneo em que o sociocultural se faz presente com a riqueza de seus personagens e formas de relação.

Desse modo, torna-se possível conceber como a subjetivação de um acontecimento em forma de cena que se configura com vários desdobramentos implica diferentes maneiras de relação entre a dimensão individual e a social na subjetividade de uma pessoa. Se, por um lado, Adriane se dá conta da revolta quanto a tal violência e o segredo da família, com o sentido dominante de "ser roubada" por eles (ou seja, um processo com dominância de sua produção subjetiva individual), por outro, concretiza importantes referências da trama social de sua família em sua própria subjetividade: a dinâmica de segredo, o patriarcalismo, a violência e os papéis de gênero passaram a se organizar, em seu cenário subjetivo, a serem ancorados no corpo, particularmente na região maxilar, e a ocupar espaços importantes em diferentes momentos de suas trocas sociais, como diante do casamento (no qual o poder de decisão cabia, em maior grau, ao marido, até por razões econômicas), à maternidade (cuidados acentuados de proteção e também muitos segredos) e à profissão (sempre em segundo plano quanto às obrigações maternais e familiares).

Em outras palavras, essa existência do social no seio da individualidade implica a existência de uma série de relações entre a paciente, sua família e o agressor que, a bem dizer, encarnaram em sua própria corporeidade, trazendo as pautas de tirania, medo intenso, segredo e tentativas de proteção que caracterizaram a violência por ela sofrida. Eles se configuram enquanto "daimons" de sua subjetividade (MORIN, 1991, p. 113-129), personagens ou seres-ideias de seu mundo vivido com os quais ela estabelece diferentes formas de relação.

Tal pluralidade da constituição subjetiva consiste num dos pontos mais importantes para se considerar a autonomia do sujeito. A diversidade de "daimons" não deve implicar necessariamente um mergulho na fragmentação esquizofrênica (GALLAGHER; ZAHAVI, 2008, p. 160), nem tampouco uma radicalidade ligada às múltiplas personalidades (HACKING, 2000, p. 18). Trata-se muito mais de uma polifonia que faz parte da constituição subjetiva das pessoas que remete às formas de pertencimento a seu nicho cultural, como também às suas possibilidades de negociar sua própria emancipação. Desse modo, tais personagens presentes em seu mundo e ligados aos acontecimentos sociais, não levaram Adriane a entrar em conflito quanto a se reconhecer em sua identidade, mas implicaram na construção de uma relação de tirania em que o sofrimento ligado à violência comprometeu parcialmente sua autonomia, em momentos como o do pânico na cena que a assolou durante a intervenção odontológica.

O sofrimento paralisante junto ao dentista parecia re-editar a cena de violência efetuada pelo tio, de maneira que ambas as situações a subjugavam, impedindo que se movimentasse em seu próprio cenário subjetivo. No entanto, 
por meio do processo hipnótico, Adriane realizou importantes modificações nas pautas interativas que reduziram, em larga medida, a influência nefasta do agressor ainda vivo em seu mundo, adotando ações capazes de influenciá-lo, como nos momentos em que pôde queimar o tio nas lavas do vulcão, implicando na produção de novos e importantes sentidos subjetivos sobre a temática.

Essa retomada de autonomia face a uma experiência de grande sofrimento, em termos de caráter ativo e de agenciamento, implica no caráter dialógico da produção subjetiva, uma vez que tanto as mudanças referentes às cenas da violência, como suas novas posturas quanto ao relacionamento com o marido, contribuem para novas configurações subjetivas produzidas pela paciente, criando alternativas importantes de relação no mundo microssocial. Daí porque a articulação entre os sentimentos de revolta, indignação e exigência de reparação, que passam a assumir um papel dominante em suas configurações, são produções singulares da paciente enquanto sujeito, mas também consistem em elementos constitutivos de novas pautas interativas, nas quais a paciente não aceita mais o tipo de submissão presente em seu casamento. Torna-se, portanto, possível sustentar que não existe uma separação abrupta entre o interior do indivíduo e o exterior social, uma vez que tanto a noção de subjetividade como a de sentido subjetivo permitem conceber que existe algo de social no seio das produções do sujeito e que existe algo dessas produções do sujeito na construção do tecido social.

Tais questões trazem à tona a necessidade de se compreender que as imagens consistem em processos que configuram, de uma só vez, as dimensões individual e social. A dor e o pânico ligados ao problema dentário de Adriane podem ser concebidos enquanto processos individuais, posto que a forma de vivenciá-los e produzir sentidos sobre os mesmos é singular e único desta pessoa, mas, ao mesmo tempo, apontam para toda uma trama familiar e processos culturais presentes em sua sociedade. Se o sujeito configura, de modo muito particular, suas vivências, de tal maneira que possa considerá-las, em certo sentido, como inteiramente suas, elas também são uma forma de o social se fazer presente em seu mundo, podendo fundar ali importantes referências da constituição de sua subjetividade.

\section{CONSIDERaÇões Finais}

O pensar complexo, tal como aqui discutido, pode não parecer novidade para muitos clínicos, uma vez que a busca de relação entre dimensões como as aqui apontadas sempre esteve presente nas considerações de importantes autores desde os primórdios da clínica sob as aspirações da ciência moderna (ELLENBERGER, 1970, p. 77-78; NEUBERN, 2009b, p. 44-51; ROUSTANG, 2000, p. 133). Entretanto, mesmo entre autores contemporâneos, parece existir e persistir a tônica de uma considerável lacuna de reflexão epistemológica e teórica que proporcione uma articulação conceitual rigorosa entre tais dimensões de maneira a conceber uma relação dialógica entre elas, as condições de autonomia que desenvolvem entre si, como também o complexo jogo que estabelecem. Sem isso, corre-se facilmente o risco de que a relação entre os polos se configure 
como dicotomia, seja pela anulação de uma pela outra (onde uma é considerada epistemologicamente menos importante, um subproduto ou efeito), seja por uma oposição irreconciliável entre elas.

Desse modo, não é suficiente considerar, como no relatado sobre Adriane, que o corpo está na mente, como a mente está no corpo, uma vez que as condições conceituais e teóricas destas relações precisam se fazer claras para que corpo e mente não sejam dissolvidos um no outro (NEUBERN, 2004, p. 139; 2010, p. 522). Assim, ao mesmo tempo em que o próprio sistema vital ligado ao maxilar, envolvendo um largo aprendizado entre seus componentes musculares, ósseos, nervosos, epiteliais e emocionais, não perde sua autonomia e produz signos específicos (ícones e índices, no caso) como intenso medo, sensações e imagens, o mesmo também se articula e integra com todo um conjunto de registros simbólicos de ordem sociocultural, gerando novos sentidos subjetivos, de maneira a compor uma larga malha configuracional de experiências vividas, em que diferentes níveis se interpenetram sem se diluírem e atuam na produção de signos os mais diversificados da singularidade da paciente.

Entretanto, como não há justaposição nem linearidade entre os níveis vital e simbólico (MERLEAU-PONTY, 2005, p. 166) é possível considerar que, o que se passa nos processos de configuração de um dos níveis não necessariamente possui efeito direto sobre o que a dinâmica do outro nível produz. Caso Adriane se utilizasse de algum procedimento (cirúrgico, farmacêutico ou fisioterápico) que re-organizasse seu sistema vital na região buco-maxilar, isso não implicaria a obrigatoriedade de uma resolução simbólica da cena ali encarnada; ou ainda, caso sua terapia produzisse a re-configuração do tema abuso em termos simbólicos, tal processo não necessariamente afetaria toda a dinâmica organizacional de suas configurações vitais, cuja autonomia estabelece pontos de tensão com a produção simbólica. Talvez pudesse apenas "desencarná-las" de sua subjetivação simbólica.

Semelhante autonomia faz ainda com que se considere outra questão importante: entre as dimensões de um polo constitutivo da subjetividade ( entre mente e corpo) pode haver momentos provisórios de hierarquização. Em certos momentos de um processo como a psicoterapia, determinadas configurações mais ligadas a um nível de subjetivação parecem despontar como foco privilegiado de intervenção e análise, de maneira que as intervenções que priorizam outro nível podem parecer inócuas quanto a tais sistemas, não promovendo junto a eles quaisquer modificações significativas (NEUBERN, 2014, p. 147). Isso talvez permita explicar determinados fenômenos, como os porquês de a dor vivida no corpo por uma pessoa em depressão ser comumente pouco afetada por medicamentos, ou ainda os porquês de uma psicoterapia que privilegie a modificação simbólica possuir poucos efeitos num caso como o de Adriane, perpassado por exigências vitais, concretizadas em sua dor de dente.

Logo, semelhante hierarquização permite conceber que o terapeuta, em seu espírito de pesquisa, necessita eleger determinado nível de produção configuracional durante certas etapas do processo, que estes níveis possuem condições, autonomia e exigências próprias que precisam ser contempladas 
em sua abordagem daquela demanda. É daí que se pode considerar que as configurações organizadas em níveis vitais podem ativar seus processos de autonomia e reconstrução quando qualificadas a partir de contextos e intervenções que favoreçam prioritariamente a produção de índices (signos que remetem a processos de reação, automatismo, sensibilidade, movimento) enquanto as configurações simbólicas podem ser melhor contempladas por meio de processos que privilegiem o símbolo (como as metáforas, analogias e contos de história).

De modo similar, esse tecido que articula o sociocultural e o individual na produção subjetiva vai além de afirmações descompromissadas e superficiais, como "tudo é complexo" (MORIN, 1990, p. 177), em que se coloca a existência de dimensões diferentes sem se demonstrar a articulação conceitual entre elas. Não bastaria, portanto, afirmar que a cena do tio agressor seria ao mesmo tempo individual e social, sem que se apontassem os processos de autonomia que existem nas produções individuais das configurações de Adriane enquanto sujeito, como ainda na construção das formas e sistemas de relação sociais de sua família de origem e de sua família atual onde ela se integrou como participante ativa.

$\mathrm{Se}$, de fato, pode-se conceber que tal cena se constitui como um processo social, uma vez que emerge de dispositivos das relações daquela família e sua cultura, ela também é uma fabricação individual, apropriada pela paciente e integrada à sua subjetividade. Tais imagens integram-se em configurações específicas de onde emergem signos, principalmente os sentidos subjetivos, que são singulares à Adriane, de maneira que nenhum outro protagonista poderia viver a mesma experiência de mundo que ela, sentir as mesmas coisas e desenvolver os mesmos recursos para lidar com semelhante sofrimento. Logo, tanto a condição de autonomia dos sistemas individuais (MORIN, 1990, p. 287), como sua autonomia de ação enquanto sujeito no mundo social (GONZALEZ REY, 2004, p. 153-157) implicam em diferentes níveis de potencial criativo, levam a conceber que a experiência de mundo de Adriane, como a da cena da violência, é muito mais ampla do que a do cenário social, pois sua riqueza particular não se esgota nem possui relações lineares com o mesmo.

Daí a ideia segundo a qual a "parte também pode se tornar maior que o todo" (MORIN, 1990, p. 167-169), ou seja, a experiência do sujeito pode se constituir como um holograma singular do mundo social e coletivo em certo sentido mais rico e complexo do que a cena social. O que esses "daimons" de tantos protagonistas passam a significar, a partir de suas configurações, para ela não necessariamente coincide com as tramas da subjetividade social vividas por tais pessoas durante as ocorrências relatadas, mesmo que seja possível encontrar muitas relações entre as vivências de Adriane e as pautas interativas em que tomou parte. Contudo, o sujeito que, até certo ponto, cria o mundo social com seu protagonismo, também pode se tornar seu refém, como no caso aqui discutido, uma vez que os processos culturais não apenas o antecedem, como possuem um dinamismo além de suas intenções e poderes de ação que pode mesmo privar-lhe, em algum grau, de sua autonomia. 
Os complexos tecidos relacionais e contextuais que envolvem processos como violência, gênero, segredo, dinheiro, classes sociais e mandatos familiares não raro impõem uma verdadeira tirania ao sujeito que se vê arrastado e preso a determinados papéis e pautas interativas, como também por complexas configurações de sofrimento que ele mesmo pode nutrir e preservar por muito tempo com seus diferentes tipos de ação. Daí porque, seja em seus momentos de prisão ao sofrimento, seja em seus momentos emancipatórios, a produção de configurações individuais guarda sua autonomia quanto às tramas sociais, não possuindo relações de linearidade com elas.

Contudo, esse tipo de flexibilização, que prioriza a complexidade envolvida no cenário do sujeito ou dos grupos, permite conceber que noções internas, como a ação dos sujeitos, pode se articular com noções tradicionalmente ligadas ao mundo social, como contexto (NEUBERN, 2010, p. 515), pauta interativa e narrativa (ANDERSON, 1997, p. 70). A participação que Adriane desenvolve em diferentes momentos de sua vivência possui uma forma ativa de influência no sistema familiar, o que pode ser destacado com clareza em suas novas propostas de relação com o marido e na interpelação de sua família de origem. Entretanto, o impacto de semelhantes mudanças desenvolve-se a partir do funcionamento ou mesmo re-organização de tais sistemas, o que não obedece nem às intenções de Adriane, nem a seus processos de autonomia enquanto sujeito.

Assim, o que se passa frente a outro observador no seio de suas transações familiares pode possuir relações simbólicas relevantes com suas imagens, mas, certamente, pode apresentar também outras facetas de uma realidade social que não encontram correspondência em seu cenário interno. A ação do sujeito, portanto, pode compor, como tanto destacado pelos sistêmicos (VASCONCELLOS, 1995, p. 99), sistemas sociais mais amplos, com modos de produção subjetiva que vão muito além de suas construções individuais que também possuem autonomia e exigências próprias, fazendo com que "o todo também possa ser maior que a soma das partes" (MORIN, 1990, p. 167-169).

Tais considerações apontam para uma condição de autonomia entre tais dimensões, que possuem características e exigências próprias que precisam ser qualificadas em suas particularidades. Nesse sentido, além de uma necessidade de hierarquização provisória que pode se impor ao terapeuta como necessidade, há também a necessidade de uma compreensão conceitual sobre os processos de subjetivação individual e social que perpassam situações como a de Adriane. Semelhante processo de pesquisa, portanto, não pode prescindir da condição de sujeito do terapeuta, um sujeito-pesquisador que possa pensar e refletir sobre as diversas bifurcações que tal complexidade do real lhe impõe (MORIN, 1990, p. 310; NEUBERN, 2004, p. 89). É nele que o pensamento ganha vida e condições de inteligibilidade para interpelar tais polos, de modo a compreendê-los dentro de uma perspectiva dialógica. 


\section{Notas}

${ }^{1}$ A terapia hipnótica de Erickson (ERICKSON; ROSSI, 1979) valoriza a potencialidade dos sujeitos, buscando utilizar seus diferentes recursos a favor de seu processo terapêutico. Mesmo sendo hipnótica, ao invés de proferir ordens como se dá nas escolas clássicas, utiliza-se de metáforas, analogias e jogos de palavras como forma de indução de transe que consistem muito mais num convite à participação ativa dos sujeitos de modo simbólico e também vivido. Sua influência foi fundamental para o surgimento das terapias breves e das terapias sistêmicas (NEUBERN, 2004, p. 57).

${ }^{2}$ A noção de configuração aqui adotada fundamenta-se na de Gonzalez Rey (2011, p. 31) segundo a qual as configurações são sistemas que integram processos emocionais e simbólicos, cuja qualidade dominante e emergente chama-se sentido subjetivo. Porém, parte-se do princípio em que as configurações também podem produzir outros signos (PEIRCE, 1998, p. 3-9) além dos sentidos subjetivos (em tese simbólicos), como os ícones (imagens) e índices (sensações e reações).

${ }^{3}$ Essa fase da terapia pôde ser realizada por processos hipnóticos e por meio da prescrição de rituais em que conversava com os personagens ligados à cena de violência em torno de seus sentimentos e exigências de reparação. $O$ foco se dá sobre o vivido do paciente e não se coloca a questão das falsas memórias. Optou-se por isso, particularmente, pelo fato de muitos dos envolvidos já estarem mortos, pela distância geográfica quanto à cidade de sua família e pela própria resistência familiar em lidar com o assunto. Embora sua mãe houvesse confirmado o acontecido, Adriane optou por não aprofundar o assunto com ela e com uma das tias que ainda vivia.

\section{REFERÊNCIAS}

ANDERSON, H. Conversation, language and possibilities. New York: Basic Books, 1997.

CSORDAS, T. The sacred self: a cultural phenomenology of charismatic healing. Berkley: University of Califórnia Press, 1997.

CSORDAS, T. Body/Meaning/Healing. New York: Palgrave/MacMillan, 2002.

DESOILLE, R. Méthode $d u$ rêve éveillé: sublimation et acquisitions psychologiques. Paris: J. L. D’Atrey, 1938.

ELLENBERGER, H. The discovery of the unconscious. New York: Basic Books, 1970.

ELLIOT, A; LEMERT, C. The new individualismo: the emotional costs of globalization. New York: Routledge, 2009.

ERICKSON, M. Healing in hypnosis. New York: Irvington, 1983.

ERICKSON, M.; ROSSI, E. Hypnotherapy: an exploratory casebook. New York: Irvington, 1979.

FERRARI, D.; VENCINA, T. O fim do silêncio na violência familiar. São Paulo: Ágora, 2002.

FOUCAULT, M. La naissance de la clinique. Paris: PUF, 2000. 
GALLAGHER, S. How the body shapes the mind. New York: Clarendon, 2005.

GALLAGHER, S.; ZAHAVI, D. The phenomenological mind. New York: Routledge, 2008.

GERGEN, K. Realidady relaciones. Barcelona: Paidós, 1996.

GONZALEZ REY, F. Problemas epistemológicos de psicología. La Habana: Academia, 1996.

GONZALEZ REY, F. O social na psicologia e a psicologia social. Petrópolis, RJ: Vozes, 2004.

GONZALEZ REY, F. Psicoterapia, subjetividade e pós-modernidade. São Paulo: Thomsom, 2007.

GONZALEZ REY, F. Subjetividade e saúde: superando a clínica da patologia. São Paulo: Cortez, 2011.

GOOLISHIAN, H.; ANDERSON, H. Narrativa e self: alguns dilemas pósmodernos da psicoterapia. In: FRIED-SCHNITMAN, D. (Org.). Novos paradigmas, cultura e subjetividade. Porto Alegre: Artes Médicas, 1996. p. 191202.

HACKING, I. Múltiplas personalidades e ciências da memória. São Paulo: J. Olímpyo, 2000.

JOHNSON, M. The body in the mind: the bodly basis of meaning, imagination and reason. Chicago: Chicago Universtity Press, 1987.

MERLEAU-PONTY, M. La structure du comportement. Paris: PUF, 2005.

MERLEAU-PONTY, M. Phénoménologie de la Perception. Paris: Gallimard, 2008.

MORIN, E. Science avec conscience. Paris: Seuil, 1990.

MORIN, E. La méthode: les idées. Paris: Seuil, 1991. v. 4.

MORIN, E. La méthode: 1'humanité de l'humanité. Paris: Seuil, 2001. v. 5.

NEUBERN, M. La psychologie clinique dans la crise du paradigme dominant: du malaise aux possibilités épistémologiques. Psychotherapies, v. 23, n. 2, p. 81-88, 2003. 
NEUBERN, M. Complexidade e psicologia clínica: desafios epistemológicos. Brasília: Plano, 2004.

NEUBERN, M. Hipnose, dor e subjetividade: questões teóricas e clínicas. Psicologia em Estudo, [S.1.], v. 14, n. 2, p. 303-310, 2009a.

NEUBERN, M. Psicologia, hipnose e subjetividade: revisitando a história. Belo Horizonte: Diamante, 2009b.

NEUBERN, M. Psicoterapia, dor e complexidade: construindo o contexto terapêutico. Psicologia: Teoria \& Pesquisa, [S.1.], v. 26, n. 3, p. 515-523, 2010.

NEUBERN, M. Fenomenologia, hipnose e dores crônicas: passos para uma compreensão clínica. Estudos e Pesquisas em Psicologia, v. 14, n. 1, p. 144-167, 2014.

PAGES, M. Complextié, conflitualité, intégration. In: DELOURNE, A. (Org.). Pour une psychothérapie plurielle. Paris: Retz, 2001. p. 57-72.

PEIRCE, C. Signs. In:__. Selected philosophical writings. Bloomington: Indiana University Press, 1998, p. 4-10.

ROUSTANG, F. La fin de la plainte. Paris: Odile Jacob, 2000.

SARTRE, J.-P. L'imaginaire. Paris: Gallimard, 2005.

VASCONCELLOS, M. J. Terapia familiar sistêmica: bases cibernéticas. Campinas, SP: PsyII, 1995.

WHITE, M. Maps of narrative practice. New York: Norton \& Company, 2007.

Recebido em: 05 de setembro de 2012 Aceito em: 30 de junho de 2014 